remember that with special and local knowledge comes the responsibility of basing it on the secure foundation of the essential unity of neural function. The neurotic tachycardia that intrigues the cardiologist may be one only of the constituents of a nervous syndrome; the acute visceral symptoms for which the surgeon performs a laparotomy may be explained by the detection of Argyll Robertson pupils and the absence of the knee-jerks. Nor is the neurologist's task less onerous; what if he misinterprets and treats as hysterical the rapid heart's action of auricular fibrillation, or fails to discover the neoplastic basis for the symptoms of his gastric neuropath?

We must aim at harmony in medical diversity, and cultivate consultative intercourse. It is our hope and belief that if in all that pertains to the nervous system interchange of opinion and knowledge from differing standpoints is freely prosecuted, the mental horizon both of the neurologist and of those other workers, practitioners and specialists, whose circles of activity impinge so definitely on his own, will be materially widened, to the enduring advantage alike of physician and of patient.

\title{
THE PRESENT POSITION OF PSYCHOPATHOLOGY.
}

Psychopathology is a science of comparatively recent growth. So long as psychology was dominated by sterile academic conceptions, no fruitful application to the problems of practical medicine was possible, and such an application had to await the advent of a psychology in touch with the actual realities of life. In the last halfcentury a psychology of this type has developed, largely owing to the work of medical men whose main concern has been with the facts of mental disorder, and who found it necessary to construct principles which would serve to explain those facts. As a result of these labours a body of knowledge has now arisen to which the name of science may reasonably be applied.

Psychopathology has not yet achieved, however, a solid foundation of universally accepted principles. There is much divergence of opinion, not only as to method and technique, but even as to fundamental postulates; and in endeavouring to form any adequate estimate of the present position of psychopathology, many different schools of thought have to be reckoned with.

First amongst these schools must be placed that of Freud : not because of the number of its adherents-for those who accept Freud's 
teaching in its entirety are still few-but because Freud's fundamental conceptions have altered the whole trend of modern psychology and psychopathology, and it is easy to trace their influence in the writings even of men who express an uncompromising opposition to Freud's methods and practice. Next may be mentioned the schools of Jung and Adler, former followers of Freud who have now diverged materially from his standpoint. Then there are the various exponents of suggestion in one or other of its forms, the advocates of persuasion, a school which has found its chief expression in the works of Dejerine and Dubois, the school of Janet, and many others who combine in a greater or less degree the tenets of several of these authorities.

To the practitioner who has not the time and opportunity to investigate the similarities and differences existing between the various schools, the mass of conflicting opinions is naturally bewildering. Yet there is much common ground, although unfortunately it is often obscured by the uncompromising methods of exposition adopted by many writers. In this common ground the most fundamental principle is the recognition that psychological causes may produce disorder, and that in the rectification of such disorder psychological methods of treatment--the methods of psychotherapy-must necessarily be employed. The precise method advocated depends naturally upon the view taken of the psychopathology of the disorder ; but here again the divergences are not so great nor so fundamental as may at first sight appear. There is, however, a great need for co-ordination in the work of the different schools, so that the common ground may be clearly marked out and the divergences accurately defined. A further need is for co-ordination between the findings of psychopathology and the facts which have been elicited by other branches of medicine, notably neurology and endocrinology.

The dispute which has long raged as to whether mental and socalled 'functional nervous' disorders are of psychical or physical origin-a dispute which is inevitably sterile-should be replaced by a careful taking into account of the material which every method of approach-chemical, physiological, anatomical, psychological-is able to offer, and an attempt to correlate this matcrial into an harmonious whole.

Perhaps the conception which promises the most fruitful line of advance in this direction is that of biological reaction, the view that the field of mental and 'nervous' disorders is one in which disease entities in the strict sense of the word cannot profitably be distinguished, but that the clinical pictures encountered are to be regarded as different types of reaction in a psychophysical organism to the environment in which it has to live. In the derelopment of such a 
conception it may be hoped that all the facts ascertained, whether they be chemical, anatomical, physiological, or psychological, will fall into place and be capable of correlation one with another.

One of the chief objects of the Journal is to help in this coordination and correlation. It is not identified with the views of any particular school, and will be ready to receive contributions from every source. An attempt will be made, moreover, by means of abstracts and critical digests, to present a review of the work which is being carried out by each of the various schools. In these ways it is hoped that the linking together of the different lines of attack will be facilitated, and that it will be found possible to attain to that comprehensive and catholic view which we feel to be indispensable for progress. 